\title{
Diyet ve Egzersizin Aksaray da yaşayan Çocuklarda Obezite Üzerine Etkisi
}

The Effect of Diet and Exercise on Obesity in Children Living in Aksaray

${ }^{1}$ Hüseyin Erdal, ${ }^{2}$ Mehmet Semih Demirtaş,

${ }^{1}$ Aksaray Üniversitesi Tip Fakültesi, Tibbi Genetik Anabilim Dalı, Aksaray, Türkiye

${ }^{2}$ Aksaray Üniversitesi Eğitim ve Araștırma Hastanesi, Cocuk Sağlığı ve Hastalıkları, Aksaray, Türkiye
Correspondence:

Hüseyin ERDAL

Aksaray Üniversitesi Tip Fakültesi,

Tibbi Genetik Anabilim Dal,

Aksaray, Türkiye

e-mail: herdalyfa@gmail.com

\section{Özet}

Aşırı kilo ve obezite şişmanlık olarak tanımlanmaktadır. Bu durum hem çocukların hem de yetişkinlerin sağlık durumlarını bozmaktadır. Biz bu çalıșmada obez çocuk hastalarda diyet ve egzersiz uygulamasının etkilerini incelemeyi amaçladık. Tanımlayıcı tipteki bu çalışmanın örneklemi Aksaray Üniversitesi Çocuk Sağlığı ve Hastalıkları polikliniğine Kasım 2019-Aralık 2020 tarihleri arasında kilo alma/obezite şikayeti ile başvuran 30 hasta ile retrospektif olarak toplandı. Çalışmaya katılan katılımcılara, obez/aşırı kilolularda önerilen FITT (sıklık, zaman, tip, şiddet) egzersiz programı uygulanmıștır. İki ay sonra kontrole çağrılan hastaların Homeostasis Model Assessment of Insulin Resistance (HOMA-IR), kilo ve rutin kan tetkikleri tekrarlandı. Hastaların kilo farklarına bağlı olarak HOMA-IR deki değişimleri incelendiğinde pozitif yönde ve anlamlı bir korelasyon saptandı $(r=0.583 ; p=0.001$, Erkek ve kız hastalar için kilo farklarına bağlı olarak HOMA-IR deki değişimlere bakıldığında sırasılyla $(r=0.624 ; \mathrm{p}=0.013)$ ve $(\mathrm{r}=$ $0.682 ; \mathrm{p}=0.005$ ) pozitif yönde anlamlı korelasyon tespit edildi. Trigliserit ve HOMA-IR arasında anlamlı ve pozitif yönde bir korelasyon saptandı $(\mathrm{r}=0.721, \mathrm{p}=0.001)$. HDL ve HOMA-IR arasındaki ilişkiye diyet + egzersiz öncesi bakıldı̆̆ında anlamlı ve negatif yönde korelasyon $(\mathrm{r}=-0.551, \mathrm{p}=0.002)$, diyet + egzersiz sonrası bakıldı̆̆ında ise anlamlı ve negatif yönde korelasyon saptand $(\mathrm{r}=-0.443, \mathrm{p}=0.014)$. LDL ve HOMA-IR arasında korelasyon saptanmadı $(\mathrm{r}=-0.234, \mathrm{p}=0.260)$. İnsülin ve HOMA-IR arasında pozitif ve yüksek oranda anlamlı bir korelasyon saptandı $(r=0.981, p=0.0001)$. LDL kolesterol ve kilo verme arasında belirgin bir korelasyon saptanamamasına rağmen $(\mathrm{r}=,-0.091, \mathrm{p}=0.664), 2$ aylık aile temelli diyet + egzersiz tedavisi yaklaşımı onucunda LDL kolesterol düzeylerinde anlamlı bir düşüşün olması bu çalışmada saptanan önemli sonuçlardan birisi idi $(r=0.725, p=0.0001)$,

Anahtar Kelimeler: Diyet; egzersiz; HOMA-IR; obezite; çocuk; adölesan

\section{Abstract}

Overweight and obesity are defined as being overweight. This situation impairs the health status of both children and adults. In this study, we aimed to examine the effects of diet and exercise on obese children. The sample of this descriptive study was retrospectively collected with 30 patients who were admitted to the Aksaray University Pediatrics outpatient clinic between November 2019-December 2020 with complaints of weight gain / obesity. FITT (frequency, time, type, severity) exercise program was applied to the participants in the study in obese / overweight patients. Homeostasis Model Assessment of Insulin Resistance (HOMA-IR), weight and routine blood tests were repeated for the patients who were called for control two months later. When the changes in HOMA-IR due to the weight differences of the patients were examined, a positive and significant correlation was found $(\mathrm{r}=0.583$ $p=0.001$, ). When the changes in HOMA-IR due to weight differences for male and female patients were examined, a positive significant correlation was found $(r=0.624 ; \mathrm{p}=0.013)$ and $(\mathrm{r}=0.682 ; \mathrm{p}=0.005)$, respectively. A significant and positive correlation was found between triglyceride and HOMA-IR $(r=0.721, p=0.001)$. When the relationship between HDL and HOMA-IR was examined before diet + exercise, there was a significant and negative correlation $(r=-0.551, p=0.002)$, and a significant and negative correlation after diet + exercise $(r=-0.443, p=0.014)$. There was no correlation between LDL and HOMA-IR $(r=-0.234, p$ $=0.260)$. A positive and highly significant correlation was found between insulin and HOMA-IR $(r=0.981, p=0.0001)$. Although no significant correlation was found between LDL cholesterol and weight loss $(r=-0.091, p=0.664)$, a significant decrease in LDL cholesterol levels after a 2-month family-based diet + exercise therapy approach was one of the important results found in this study $(\mathrm{r}=.0 .725, \mathrm{p}=0.0001)$.

Keywords: Diet; exercise; HOMA-IR; obesity; children; adolescent 


\section{Giriş}

Aşırı kilo ve obezite şişmanlık olarak tanımlanmaktadır. Bu durum hem çocukların hem de yetişkinlerin sağlık durumlarını bozmaktadır. Son on yılda obezitedeki artışın, metabolik ve kardiyovasküler hastalık riskini artırdığı tespit edilmiş, ve bu durumun yüksek sağlık harcama maliyeti ve yaşam kalitesindeki azalma ile ilişkili olduğu gösterilmiştir $(1,2)$. Küresel anlamda obezite, giderek artan oranda çocuk popülasyonunu etkilemektedir. Benzer şekilde ülkemizde de çocuk ve gençlerde obezite riskinin daha fazla olduğu gösterilmiştir (3). $\mathrm{Bu}$ durumun meydana gelmesinde hazır gida ile beslenme, sedenter yaşam tarzı, elektronik cihazların aşırı kullanımı, sosyoekonomik durum ve fiziksel aktivite eksikliği çok önemli bir rol oynamaktadır (4). Gelişmekte olan ülkelerde çocuk yaş grubunda obezite sayısındaki artış ciddi bir sorun olarak ortaya çıkmakta ve bu durumla mücadele edebilmek için çeşitli strateji planları yapılmaktadır. Buradaki amaç hem ekonomik olarak ortaya çıkan yüksek maliyetin azaltılması hem de bireylerin sağlıklı bir yaşam sürmesinin teşvik edilmesidir. Avrupa Bölgesi'ndeki tüm yetişkinlerin yarısı ve çocukların ise beşte biri aşırı kiloludur. Bu çocukların da üçte biri obez olup, rakamlar hızla artmaktadır (5). Dünya Sağlık Örgütü (DSÖ) Avrupa Bölgesi'nde üye ülkeler tarafından okul çağı çocuklarının şişmanlık durumlarını izlemek amacıyla, 2010 yılında yapılan çocukluk dönemi şişmanlığın izlenmesi araştırmasında okul çağı çocuklarının \%40'ına yakınının vücut ağırlığının normalin üzerinde olduğu, bu çocukların \%15'inin de obez olduğu belirtilmiştir (6). Türkiye İstatistik Kurumunun 2016 yılında yaptığı çalışmaya göre Türkiye'de 15 yaş ve üzeri obez bireylerin oranı \%19,6 olarak gösterilmiştir (7).

Fiziksel aktivite ve diyet, obezitenin önlenmesinde ve yönetilmesinde adeta bir köşe taşıdır (8). Büyüme çağında optimum beslenme ve fiziksel aktivitenin birlikte uygulanması sağlıklı bir fiziksel büyümeyi sağlayarak, obezite riskini azaltmaktadır. Çocuklarda yüksek düzeyde enerji harcanmasını sağlayan fiziksel aktivite, çocukların sağlıklı kilo durumuyla doğrudan ilişkili olup, aynı zamanda çocukların klinik sonuçlarıyla da koreledir. Düşük fiziksel aktivite tipik olarak artmış kardiyo-metabolik ve vasküler hastalık riski ile ilişkilidir. $\mathrm{Bu}$ nedenle, hem normal kilolu hem de fazla kilolu çocukların fiziksel aktivite ve egzersiz seviyelerinin artırılması ve oturma sürelerinin azaltılması, aşırı kilo alımını önlemeye yardımcı olacaktır $(9,10)$. Çocukluk çağında ortaya çıkan obezite ciddi sağlık sorunlarına neden olmakta ve erken dönemde müdahale edilmez ise olumsuz sonuçlar doğurmaktadır. Vücudun organ ve sistemlerini olumsuz yönde etkilemekte olup, hipertansiyon, insülin direnci, Tip 2 diyabet mellitus ve karaciğer yağlanması gibi durumlara neden olmaktadır (11).

$\mathrm{Bu}$ çalışmada obez tanısı alan çocuk hastalarda diyet ve egzersiz uygulamasının etkilerini incelemeyi amaçladık.

\section{Gereç ve Yöntemler}

\section{Örneklem}

Tanımlayıcı tipteki bu çalışmanın örneklemi Kasim 2019- Kasim 2020 tarihleri arasinda Aksaray Üniversitesi Çocuk Sağlığı ve Hastalıkları polikliniğine ilk başvurusunda, kilo alma/obezite şikayeti ile başvuran 40 hastadan retrospektif olarak dosya taraması ile yapılmas1 planlanıldı. 2 ay sonraki kontrol muayenesine gelmediği tespit edilen 6 hasta ve çalışmada verilerinin kullanılmasına onay vermeyen 4 hasta çalışmadan çıkarılmış ve toplamda 30 katılımcı ile çalışma yapılmıştır.

\section{Verilerin toplanmast}

Polikliniğe başvuran hastaların rutin muayeneleri yapılmış, ek bir hastalığı bulunmayan 10-18 yaş arasında kilo alma/verememe şikayetiyle polikliniğe başvuran hastalar arasından gönüllülük esasına göre belirlenmiştir. İlk başvuru esnasında hastaların kiloları Neyzi'nin (12) 2015 Türk Çocuklarında Persentil değerlerindeki referans aralıklarına göre yaş/cinsiyete göre değerlendirilmiş, $>97$ persentil olan hastalar çalışmaya dahil 
edilmiştir. Kilosu +2 standart sapmanın altında kalanlar, ek hastalığı olanlar, çalışmaya katılmak istemediklerini beyan etmiş olanlar ve kontrol muayenesine başvurmamış olanlar çalışmaya dâhil edilmemiştir.

Çalışmaya katılan katılımcılara, obez/aşırı kilolularda önerilen, orta şiddette FITT (sıklık, zaman, tip, şiddet) egzersiz programı uygulanmıştır (16). Bu kapsam dahilinde hastalara rutin olarak aerobik egzersiz tipinde kondisyonu sağlaması adına, günlük 10.000 adım atması veya haftada 3 gün en az $30 \mathrm{dk}$. süre ile bisiklet sürülmesi 2 aylık ( 8 haftalık) rutin takipleri süresince, ebeveyn gözetiminde yaptırılmıştır (17). Ailelerden bu konuda gözlemci olması ve gerektiğinde bireye eşlik ederek teşvik edilmesi sağlanmıştır. 2 ay sonunda muayene gelen hastalardan egzersiz faaliyetlere uyup uymadığı aile ile birlikte değerlendirilmiş, rutin egzersiz programına uymayan katılımcılar çalışmaya dahil edilmemiştir. Katılımcıların uygulayacağ 1 diyet bireyin ve ailenin yeme örneği baz alınarak, ve ailenin sosyo-ekonomik durumu da göz önünde bulundurularak, her bireye özel olarak hazırlanmıştır. Diyet hazırlanırken çocuğun büyüme ve günlük aktivitesi de göz önüne alınarak, gerekli besin maddelerini içermesine, ve günlük verilen diyetin ortalama kalori düzeyinin 1500-1800 arasında olmasına dikkat edilmiştir. Uygulanan diyet listesi diyetisyen tarafından hazırlanmıştır.

Hastalardan tam kan sayımı (CBC), Aspartat transaminaz (AST) ve Alanin transaminaz (ALT), düşük dansiteli lipoprotein (LDL), yüksek yoğunluklu lipoprotein (HDL) İnsülin, glukoz, kan üre azotu (BUN), kreatinin, Trigliserit, serbest T4 düzeyi, Tiroit Stimülan Hormon (TSH) bakildı Hastaların Homeostasis Model Assessment of Insulin Resistance (HOMA-IR) indeksi, Açlık İnsülin (mIU/L)xAçlik Kan Şekeri (mg/dL)/405 formülüne göre hesapland1. Diyetisyene yönlendirilen ve diyetleri kendilerine uygun şekilde hazırlanılan hastalar poliklinikte "HEEADSS" uygulamas1 (13) ile uygun ortam ve mahremiyet gözetilerek mevcut durum ve tedavi planı aile ile birlikte hastalara anlatıldı. Hastaların verilen diyet tedavisinin yanında yapacakları günlük veya haftada 3 gün olacak şekilde aktivite/egzersiz planları düzenlendi. Ailenin diyet ve egzersiz planlarının gerçekleşmesinde bireye yardımcı olması gerekliliği anlatıldı ve çalışmada pozitif yönlü motivasyon açısından destekleri istenildi. 2 ay sonra kontrole çağrilan hastaların kilo ölçümleri, rutin kan tetkiklerine tekrar bakıld1 ve hastalar ile diyete uyum, egzersiz durumları birlikte değerlendirildi. Ailelerden bu dönem zarfinda "diyete uyum, destek ve motivasyon" konularında ayrıntılı olarak bilgi alınd1.

\section{Etik}

Katılımcılara araştırma ile ilgili gerekli açıklama ve çalışma prosedürleri anlatıldıktan sonra, tüm katılımcılardan yazılı bilgilendirilmiş onam alınmıştır. Bu çalışma Dünya Tıp Birliği Etik Kurallarına (Helsinki Bildirgesi) uygun olarak gerçekleştirilmiştir. $\mathrm{Bu}$ anket Hatay Mustafa Kemal Üniversitesi Etik Kurulu tarafindan (2021-05) onaylanmıştır. Katılımcılara, katılımlarının gönüllü olduğu ve verilerin anonimlik, mahremiyet ve gizliliğinin garanti edildiği konusunda güvence verildi. Ayrıca, katılımc1lar/aileler yazılı bir bilgilendirilmiş onam imzalanmadan önce çalışmanın amacı ve yöntemi hakkında bilgilendirildiler.

\section{İstatistiksel analiz}

Çalışma verilerinin istatistiksel analizinde IBM SPSS Statistics (Statistical Package for the Social Sciences versiyon 22, Chicago, IL, USA) programı kullanılmıştır. Çalışmamızda nicel verilere ilişkin tanımlayıcı istatistiklerde ortalama, standart sapma, minimum, maksimum değerleri verilmiştir. Sürekli verilerin normal dağılıma uygunluğunun incelenmesinde Shapiro-Wilk testinden yararlanılmıştır. Nitel değişkenler arasındaki ilişki ki-kare analizi ile incelendi. $p<0,05$ olarak elde edilen sonuçlar anlamlı kabul edildi. Normal dağılıma uyan veriler arasında Pearson korelasyon analizi uyguland.

\section{Bulgular}

Çalışmaya dahil edilen erkek ve kız hastaların ortalama yaşı sırasıyla $11.67 \pm 2.61$ ve 13.40 \pm 2.50 idi. Erkek ve kız hastaların ALT ve AST ortalamaları sirasiyla $(25.87 \pm 8.99$; 
$27.20 \pm 8.43 \mathrm{U} / \mathrm{L})$ ve $(15.60 \pm 5.23 ; 21.0 \pm 5.26$ $\mathrm{U} / \mathrm{L})$ idi. Bunun yanında hastaların TSH ortalamaları $3.06 \pm 1.31 \mu \mathrm{IU} / \mathrm{mL}$, total kolesterol ortalamaları ise $175.93 \pm 28.15$ $\mathrm{mg} / \mathrm{dL}$ idi. Hastaların egzersiz öncesi ve sonras1 trigliserit ortalamalar1 $125.32 \pm 70.17$ $\mathrm{mg} / \mathrm{dL}$ ve $118.36 \pm 54.11 \mathrm{mg} / \mathrm{dL}$ idi. Çalışmamızdaki hastaların HDL ortalamaları sirasiyla $48.23 \pm 9.03 \mathrm{mg} / \mathrm{dL}$ idi. Hastaların diyet + egzersiz öncesi LDL kolesterol ortalamalar1 105. $\pm 27.44 \mathrm{mg} / \mathrm{dL}$ ve diyet + egzersiz sonras1 LDL ortalamaları ise 101.14 $\pm 29.58 \mathrm{mg} / \mathrm{dL}$ idi. Total kolesterol ortalamaları ise $175.93 \pm 28.15 \mathrm{mg} / \mathrm{dL}$, ortalama glukoz değerleri ise $89.36 \pm 8.40$ $\mathrm{mg} / \mathrm{dL}$ idi. Bunun yanında erkek ve kız hastaların ortalama kilosu sirasiyla $78,0 \pm$ $18,84 \mathrm{~kg}$ ve $72,83 \pm 12,28 \mathrm{~kg}$ idi. Çalışmamızdaki hastaların kilo farkları $2.43 \pm$ $2.55 \mathrm{~kg}$, trigliserit farkları $-1.40 \pm 4.43 \mathrm{mg} / \mathrm{dL}$ ve HOMA-IR farkları ise $1.93 \pm 2,68$ idi. Erkek hastaların kilo farkları $2.66 \pm 2.72 \mathrm{~kg}, \mathrm{k} 1 \mathrm{z}$ hastaların ise $2.20 \pm 2.45 \mathrm{~kg}$ idi. Trigliserit farkları ise erkek hastalar için $0.46 \pm 51.22$ $\mathrm{mg} / \mathrm{dL}, \mathrm{k}$ z hastalar için $-3.26 \pm 38.19 \mathrm{mg} / \mathrm{dL}$ idi. HOMA-IR farkları erkek hastalar için $2.30 \pm 3.64$, kız hastalar için $1.56 \pm 1.13$ idi. İkinci bakılan lipit profili değerlerinde kolesterol seviyesi $>200 \mathrm{mg} / \mathrm{dl}$ üzerinde olan 3 hastamizda (\%10) hiperkolesterelomi saptand. Erkek ve kız çocukların diyet + egzersiz öncesi ve diyet + egzersiz sonras1 lipit parametreleri karşılaştırılmıştır (Tablo 2; Tablo 3).

Farklar, egzersiz + diyet sonrasındaki ölçümlerden egzersiz + diyet öncesi yapılan ölçümler çıkarılarak elde edildi. Hastaların kilo farklarına bağlı olarak HOMA-IR deki değişimleri incelendiğinde pozitif yönde ve anlaml1 bir korelasyon saptand $1 \quad(r=0.583$; $\mathrm{p}=0.001$, Figür $1-\mathrm{a})$. Erkek ve k1z hastalar için kilo farklarına bağlı olarak HOMA-IR deki değişimlere bakıldığında sırasıyla $(r=0.624$; $\mathrm{p}=0.013$, Figür $1-\mathrm{b})$ ve $(\mathrm{r}=0.682 ; \mathrm{p}=0.005$, Figür 1-c) pozitif yönde anlamlı korelasyon tespit edildi. Trigliserit ve HOMA-IR arasinda anlamlı ve pozitif yönde bir korelasyon saptand $1(r=0.721, p=0.001$, Tablo 1). HDL ve HOMA-IR arasındaki ilişkiye diyet + egzersiz öncesi bakıldığında anlamlı ve negatif yönde korelasyon $(\mathrm{r}=-0.551, \mathrm{p}=0.002)$; diyet + egzersiz sonrası bakıldığında ise anlamlı ve negatif yönde korelasyon saptandı $(r=-0.443, p=0.014)$. LDL ve HOMA-IR arasındaki ilişkiye bakıldığında ise korelasyon saptanmad1 $(\mathrm{r}=-0.234, \mathrm{p}=0.260)$. Çalışma grubunda insülin ve HOMA-IR ilişkisi değerlendirildiğinde ise pozitif ve yüksek oranda anlamlı bir korelasyon saptand1 $(\mathrm{r}=0.981, \quad \mathrm{p}=0.0001)$. Cinsiyet üzerinden karşılaştırılma yapıldığında ise erkek hastalarda trigliserit ve HOMA-IR arasında yüksek düzeyde ve anlamlı bir korelasyon saptand $1(\mathrm{r}=0.825, \mathrm{p}=0.0001) . \mathrm{K} 1 \mathrm{z}$ hastalarda bakıldığında ise korelasyon saptanmadı $(r=0.130, p=0.658)$. Hastaların kilo farklarına bağlı olarak LDL seviyelerindeki değişim fark1 incelendiğinde, kilo fark1 ile LDL arasında ilişki saptanmadı $(\mathrm{r}=-0.091, \mathrm{p}=$ 0.664). Benzer şekilde diyet ile kilo fark1 arasındaki ilişki incelendiğinde LDL seviyeleri arasında ilişki saptanmadı $(\mathrm{r}=$ $0.151, \mathrm{p}=0.442)$. Bunun yanında diyet + egzersiz öncesi LDL düzeyleri ile diyet + egzersiz sonrasi LDL düzeyleri arasında yüksek düzeyde ve anlamlı bir korelasyon saptand 1 ( $r=0.725, p=0.0001$, HOMA).

Tablo 1. Trigiliserit ve HOMA-IR arasındaki ilişki

\begin{tabular}{|c|c|c|c|c|c|}
\hline & & Trigliserit/önce* & HOMA-IR/önce ${ }^{*}$ & $\underset{+}{\text { Trigiliserit }}$ & HOMA-IR $^{+}$ \\
\hline \multirow[t]{2}{*}{ Trigliserit/önce* } & $\mathbf{r}$ & 1 &, $721^{\&}$ &, $884^{\wedge}$ &, 554 \\
\hline & p & &, 000 &, 000 & ,002 \\
\hline \multirow[t]{2}{*}{ HOMA-IR /önce ${ }^{*}$} & $\mathbf{r}$ &, $721^{\&}$ & 1 &, $655^{\&}$ &, $778^{\&}$ \\
\hline & p &, 000 & &, 000 &, 000 \\
\hline \multirow[t]{2}{*}{ Trigliserit $^{+}$} & $\mathbf{r}$ &, $884^{\wedge}$ &, $655^{\&}$ & 1 &, 523 \\
\hline & p &, 000 &, 000 & &, 003 \\
\hline \multirow[t]{2}{*}{ HOMA-IR ${ }^{+}$} & $\mathbf{r}$ & ,554 &, $778^{\&}$ & ,523 & 1 \\
\hline & p &, 002 &, 000 &, 003 & \\
\hline
\end{tabular}



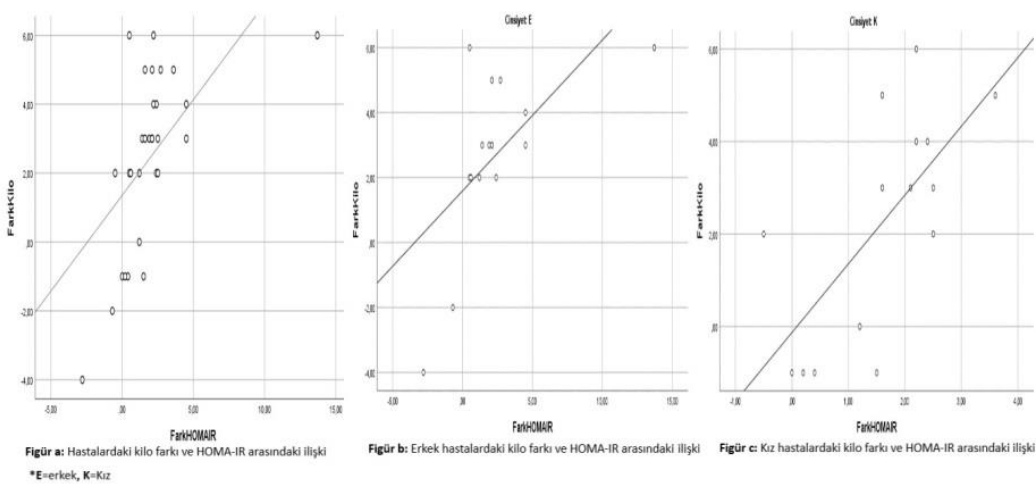

Figure 1. Kilo fark1 ve HOMA-IR arasındaki ilişki

Tablo 2. LDL ve HOMA-IR arasındaki ilişsi

\begin{tabular}{|c|c|c|c|c|c|}
\hline & & HOMA-IR/önce* & HOMA-IR $^{+}$ & LDL/önce* & $\mathrm{LDL}^{+}$ \\
\hline \multirow[t]{2}{*}{ HOMA-IR/önce } & $\mathbf{r}$ & 1,000 & 0,537 & $-0,100$ & $-0,168$ \\
\hline & p & & 0,002 & 0,635 & 0,392 \\
\hline \multirow[t]{2}{*}{ HOMA-IR ${ }^{+}$} & $\mathbf{r}$ & 0,537 & 1,000 & $-0,253$ & $-0,187$ \\
\hline & p & 0,002 & & 0,223 & 0,341 \\
\hline \multirow[t]{2}{*}{ LDL/önce* } & $\mathbf{r}$ & $-0,100$ & $-0,253$ & 1,000 & 0,813 \\
\hline & p & 0,635 & 0,223 & & 0,000 \\
\hline \multirow[t]{2}{*}{$\mathbf{L D L}^{+}$} & $\mathbf{r}$ & $-0,168$ & $-0,187$ & 0,813 & 1,000 \\
\hline & p & 0,392 & 0,341 & 0,000 & \\
\hline
\end{tabular}

Tablo 3. Erkek çocuklarda diyet + egzersiz öncesi ve sonrası lipit parametrelerin karşılaştırılması

\begin{tabular}{|c|c|c|c|}
\hline Parametreler & $\begin{array}{c}\text { Diyet +egzersiz öncesi } \\
(\mathrm{n}=\mathbf{3 0})\end{array}$ & $\begin{array}{c}\text { Diyet }+ \text { egzersiz sonrası } \\
(\mathrm{n}=\mathbf{3 0})\end{array}$ & $\mathbf{p}$ \\
\hline HDL & $46.5 \pm 7.6$ & $47.1 \pm 5.9$ & 0.653 \\
\hline LDL & $108.1 \pm 29.7$ & $102.6 \pm 26.4$ & 0.380 \\
\hline Trigliserit & $135.3 \pm 74.4$ & $125.8 \pm 62.1$ & 0.223 \\
\hline Total kolesterol & $172.7 \pm 29.5$ & $176.8 \pm 26.6$ & 0.386 \\
\hline HOMA-IR & $6.3 \pm 5.1$ & $4.0 \pm 2.4$ & 0.028 \\
\hline
\end{tabular}

Tablo 4. Kız çocuklarda diyet + egzersiz öncesi ve sonrası lipit parametrelerin karşılaştırılması

\begin{tabular}{|c|c|c|c|}
\hline Parametreler & $\begin{array}{c}\text { Diyet +egzersiz öncesi } \\
(n=30)\end{array}$ & $\begin{array}{c}\text { Diyet + egzersiz sonrası } \\
(\mathbf{n}=\mathbf{3 0})\end{array}$ & p \\
\hline HDL & $50.0 \pm 10.2$ & $58.5 \pm 18.2$ & 0.125 \\
\hline LDL & $102.6 \pm 26.4$ & $99.7 \pm 33.4$ & 0.634 \\
\hline Trigliserit & $115.4 \pm 66.9$ & $110.9 \pm 45.6$ & 0.906 \\
\hline Total kolesterol & $179.1 \pm 27.4$ & $170.8 \pm 36.5$ & 0.345 \\
\hline HOMA-IR & $3.8 \pm 1.7$ & $2.3 \pm 1.1$ & 0.0001 \\
\hline
\end{tabular}




\section{Tartışma ve Sonuç}

Çocukluk çağı obezitesinin özellikle adölesan dönemde görülen siklı̆̆ında meydana gelen artış, gelişmiş ve gelişmekte olan ülkeler başta olmak üzere, dünyanın birçok ülkesinde giderek artan ciddi bir endişe kaynağıdır $(14,15)$. Obezitenin çocukluk yaş grubundaki tedavisi için farmakoterapi seçenekleri çok sinırlidir. $\mathrm{Bu}$ nedenle, uygun beslenme, egzersiz ve davranış değişikliğini vurgulayan kapsamlı bir yönetim programı oluşturmak çok önemlidir. Beslenme ve fiziksel aktiviteyi içeren yaşam tarzı değişiklikleri, çocukluk çağ 1 obezitesine yönelik tedavi yaklaşımının temeli olmaya devam etmektedir (16). Aşırı kilolu ve obez çocukların normal kilolu akranlarına göre, obez yetişkinler olma riskinin daha yüksek olduğu ve bu duruma katkıda bulunan en önemli faktörün düşük fiziksel aktivite seviyeleri olduğu gösterilmiştir $(17,18)$. Enerji dengesini düzenlemek, yani enerji harcamasına kıyasla orantısız şekilde yüksek enerji alımını tersine çevirmek için aktivite değişikliği gerekmektedir (19).

Çocuk ve ergenlerin sağlıklı büyüme ve gelişmesi için fiziksel aktivite gerekli bir uygulama olup, aşırı kilolu ve obezite olmaya yatkınlığın önlenmesinde önemli bir rol oynamaktadır. Buna bağlı olarak gelişebilecek komorbit durumların risklerini de görülmesini azaltmaktadır (20,21). 21. yüzy1lın getirdiği teknolojik gelişmeler, teknolojik cihazlar ve özellikle taşınabilir elektronik cihazların (TEC) kullanımının daha fazla olmasına ve dolayısıyla çocukların ve adölesanların enerji tüketiminin azalmasına sebep olan önemli etkenlerdir $(21,22)$. Ayrica yapılan çalışmalarda obez gençlerin, obez olmayan akranlarına göre fiziksel olarak daha az aktif olduklarını; televizyon izlemek ve diğer TEC kullanımı gibi daha az efor sarfedilen uygulamalar ile daha fazla zaman geçirdiklerini göstermektedir (23-25). Fiziksel aktivite, daha yüksek düzeyde enerji harcanması yoluyla çocukların sağlıklı kilo durumlarıyla doğrudan ilişkilidir. Bununla birlikte, fiziksel aktivite düzeyi aynı zamanda adölesan ve çocukların sağlık durumlarıyla yakından ilişkilidir. Düşük fiziksel aktivite seviyeleri tipik olarak artmış kardiyo- metabolik ve vasküler hastalık riski ile yakından ilişkilidir (26). Bundan dolayı, aşırı kilolu çocukların fiziksel aktivite ve egzersiz seviyelerini artırmaya ve oturma sürelerini azaltmaya teşvik etmek, obezite ve buna bağlı olarak gelişebilecek olan sağlık risklerini önlemeye yardımcı olacaktır (27). Obezite ile yapılan bir çalışmada (28), fiziksel aktivite ve obezite arasında iki ana bağlantı vurgulanmıș: Birinci olarak fiziksel aktivite ile günlük enerji tüketimini artırmak ile iştahı potansiyel olarak bastırmak olarak belirtilmiştir. Fiziksel aktivite ile obezite arasındaki güçlü bağlantının bir diğer açıklaması, fiziksel aktivitenin bireylerin enerji harcamalarını artırarak kilolarını daha kolay kontrol etmelerini sağlayan "karşılıklı nedensellik" olarak adlandırılan durumdur (29). Thivel ve ark.'nın yapmış oldukları çalışmada sabah saatlerinde yapılan yoğun egzersizin obez adölasanlarda enerji alım düzeyinin önemli ölçüde azaldığını göstermişlerdir. Bunun yanında yoğun egzersizin enerji alımı üzerindeki etkisinin diyet ve fiziksel aktivite sonrasında da etkisini devam ettirdiğini göstermişlerdir. $\mathrm{Bu}$ durumun obezite tedavisinde yoğun egzersiz uygulamasının negatif enerji dengesi oluşturmak için önemli bir etkisinin olduğu belirtilmiştir (30). Literatürde yapılan çalışmalarla benzer şekilde, çalışmamızda bulduğumuz önemli sonuçlardan birisi olan 2 aylık takipte önerilen fiziksel egzersiz uygulamas1 ile kilo verme arasındaki ilişki erkek çocuklarda $2.66 \pm 2.72$, k1z çocuklarda ise $2.20 \pm 2.45$ oranında bulunmuştur. Kilo vermenin HOMA-IR ile ilişkisi incelendiği zaman erkek çocuklarda $(\mathrm{r}=0.624 ; \mathrm{p}=0.013)$; k1zlarda ise $(\mathrm{r}=0.682$; $\mathrm{p}=0.005)$ pozitif yönde anlamlı korelasyon tespit edilmiştir. Spor ve fiziksel aktivite ile sağlıklı bir biçimde kilo verme kontrolü, aşırı ve kontrolsüz kilo vermeye göre vücut kondisyonunu artırır, kas-iskelet ağrısını ve rahatsızlığını azaltır. Aksi bir durumda ise fiziksel aktivite uygulamaları birey için daha zor olmaktadır (31).

Son y1llarda önemli ölçüde artan çocukluk çağı obezitesini önlemeye yönelik bir müdahale kategorisi, aile temelli müdahale kavramıdır. Bu kavram, çocukluk çağında 
obezitenin önlenmesi, değerlendirilmesi ve tedavisini içeren 15 profesyonel organizasyon tarafindan yapılan 2007 yılında bir çalışmadan kaynaklanmaktadır (32,33). Ebeveynler, çocukların enerji dengesini (diyet, fiziksel aktivite, teknolojik aletlerin kullanımı ve uyku) etkileyen dört davranışı destekleme ve yönetimindeki son derece etkili rolleri göz önüne alındığında, diyet ve tedavi müdahalelerinde yardımcı olmaktadırlar (34). $\mathrm{Bu}$ sadece ebeveynlerin uygulamalarını ve kurallarını değil, aynı zamanda çocukların bulunduğu ortamları ve ebeveynlerin kendi davranış alışkanlıklarının çocuklar tarafından benimsemesini de içerir. $\mathrm{Bu}$ incelemeler, müdahale etkinliği hakkında kapsamlı bilgiler aktarırken, bilgi tabanındaki boşlukları ortaya çıkaramazlar $(35,36)$. Obezite tedavisinde aile bazlı müdahalelerin etkin bir şekilde uygulanması tedavi gören çocuk hastaların yaş ve obezite durumu ile yakından ilişkilidir. Danielsson ver ark'nın 14-16 yaş arası adölesan çocuklarda belirli sürelerde uygulamış olduğu davranış tedavisi sonucunda, vücut ağırlığında kayda değer bir azalma görülmemiştir. Fakat, 6-8 yaş aralığında yüksek oranda obeziteye sahip çocuklarda, orta derecede obezite varlı̆̆ 1 olan çocuklar ve 14-16 yaş arası çocuklara göre kayda değer sonuçların elde edildiği rapor edilmiştir. 6-8 yaş grubundaki davranış tedavisi uygulamasının 14-16 yaş arası grubuna göre daha başarılı olduğunu göstermiştir. $\mathrm{Bu}$ durum bize iletişim ve uyum sorununun daha fazla yaşandığ $14-16$ yaş arası adölesan grupta aile bazlı tedavi yaklaşımının etkili bir yöntem olduğunu göstermektedir (37). Aile bazlı müdahaleler arasında: Ebeveynlerin çocuklarının öncelikli olarak diyet ve fiziksel aktiviteye odaklanmasını takip etmesi; elektronik alet kullanımına bağlı uyku düzeni kontrolü; arkadaşlık çevresinde ve sosyal ortamlardaki adölesanın davranışlarındaki değişimler; sosyokültürel seviyedeki değişimin takibi bu müdahaleler arasında sayılabilir $(38,39)$. Robertson ve ark.'nın 115 aile ile yapmış olduğu çalışma sonucunda, aile bazlı tedavi yaklaşımının obezite yönetiminde etkili olduğunu göstermiştir. Bunun yanında, tedavi bazlı yaklaşımın yalnızca hasta üzerinde değil aynı zamanda sağlı sistemi ve toplum üzerinde kost-efektif etkileri olduğunu da gösterilmiştir (40). Çalışmamızda uyguladığımız benzer aile tedavi yaklaşımının, diyet öncesi ve sonrasında hastaların kilo vermelerini etkilediğini anlamlı olarak bulduk ( $\mathrm{r}=0.583 ; \mathrm{p}=0.001$, Figür $1-\mathrm{a})$. Özellikle ailelerin dahil edildiği bu programda hastanın tedaviye uyumu, devamlılığı ve ailenin hasta üzerindeki olumlu etkisi gözlemlenmiştir.

Artmış total kolesterol ve LDL kolesterol seviyeleri, obez çocuklar ve adölesanlar arasında nispeten daha yaygındır. $\mathrm{Bu}$, obezitenin pediatrik hiperkolesterolemi için bir risk faktörü olarak kabul edilmesi gerektiğini ve obez çocukların anormal lipid profilleri açısından taranması gerektiğini göstermektedir (41). Obez çocuklar ve ergenler arasında hiperkolesteroleminin klinik etkileri daha iyi anlaşılmaktadır ve çocukluk dönemindeki yüksek kolesterol düzeylerinin yetişkin yaşamdaki hiperkolesterolemi ile ilişkili olduğu bilinmektedir.

Ayrıca, çocuklar ve adölesanlar arasındaki lipid anormallikleri, daha yüksek insülin direnci ve hipertansiyon riskleri ile ilişkili olup, sekonder kalp hastalıklarının gelişiminde önemli bir rol oynamaktadır (42). Lubia ve ark'nın Meksika'da 49 obez çocuk ile yapmış olduğu diyet çalışmasında dört aylık diyet uygulaması sonucunda LDL ve total kolesterol düzeylerinin azaldığını göstermiştir (43). Yapılan bir diğer randomize kontrollü çalışmada 38 obez hastadaki kolesterol seviyelerinin diyet tedavisi sonrasında azaldığı gösterilmiştir (44). Çalışmamızda 2 aylık takip süresinde diyet ve egzersiz programı sonrasinda LDL seviyelerinin azaldığını tespit etmemiz çalışmamızda bulduğumuz en önemli sonuçlardan birisi $(\mathrm{r}=0.725, \mathrm{p}=0.0001)$ olup, kilo vermenin tek başına LDL üzerinde anlamlı bir etkiye sahip olmadığ yapılan korelasyon çalışması ile gösterilmiştir $(\mathrm{r}=0.091, \mathrm{p}=0.664)$.

Sonuç olarak, obez ve aşırı kilolu adölesanlarda tek başına diyet tedavisinin yerine diyet +egzersiz uygulamasının aile temelli olacak şekilde yönetiminin, hastanın tedaviye uyum ve devamlılığı açısından önemli olduğunu gösterdik. Literatüre daha 
büyük katkı sağlamak için çocukluk çağındaki obezite ile ilgili olarak randomize kontrollü çalışmalar ile prospektif kohort çalışmalarının yapılmasının literatüre daha önemli katkılar sağlayacağını düşünmekteyiz.
- V. Uluslararasi Aksaray Sempozyumu (03-04 Kasım 2020) , Aksaray Universitesi

\section{KAYNAKLAR}

1. Hales CM, Fryar CD, Carroll MD, et al. Trends in obesity and severe obesity prevalence in US youth and adults by sex and age, 2007-2008 to 20152016. JAMA 2018;319:1723-25

2. Lavie CJ, Laddu D, Arena R, et al. Healthy weight and obesity prevention: JACC health promotion series. J Am Coll Cardiol 2018;72:1506- 31.

3. Carbone S, Del Buono, M. G Ozemek, et al. Obesity, risk of diabetes and role of physical activity, exercise training and cardiorespiratory fitness. Progress in cardiovascular diseases, 2019; 62, 327-33.

4. Güngör, N. K. Overweight and obesity in children and adolescents. Journal of clinical research in pediatric endocrinology, 2014; 6, 129.

5. European Congress on Obesity (2018). https://eco2018.easo.org/eco-highlights/

6. World Health Organization. Obesity and overweight fact sheet. WHO Media centre 2016.

7. Türkiye İstatistik Kurumu (TÜİK) (2017). http://www.tuik.gov.tr/basinOdasi/haberler/2017 31_20170607.pdf.

8. Hills AP, Byrne NM. State of the science: a focus on physical activity. Asia Pac J Clin Nutr 2006;15:40-8.

9. Hills AP, King NA, Armstrong TP. The contribution of physical activity and sedentary behaviours to the growth and development of children and adolescents: implications for overweight and obesity. Sports Med 2007; 37: 533-45.

10. Hills AP, Andersen L. B, Byrne N. M. Physical activity and obesity in children. British journal of sports medicine, 2011; 45, 866-70.

11. Han JC, Kimm SYS. Childhood Obesity-2010: Progress and Challenges. Lancet 2010; 375:173748.

12. Neyzi O, Bundak R, Gökçay G, et al. Reference Values for Weight, Height, Head Circumference, and Body Mass Index in Turkish Children. $J$ Clin Res Pediatr Endocrinol. 2015;7:280-93.

13. Smith GL, McGuinness TM. Adolescent Psychosocial Assessment: The HEEADSSS. J Psychosoc Nurs Ment Health Serv. 2017 ;1;55:2427.

14. Wang $Y$, Lobstein $T$. Worldwide trends in childhood overweight and obesity. Int $J$ Pediatr Obes 2006;1:11-25.

15. Kelishadi R. Childhood overweight, obesity, and the metabolic syndrome in developing countries. Epidemiol Rev 2007; 29: 62-76.

16. Klish WJ. Clinical evaluation of the obese child and adolescent. In:Motil KJ, Geffner M (section

eds) and Hoppin AG (Deputy ed). Up to date. www.uptodate.comc2013UpToDate.

17. World Health Organization. Obesity: Preventing and Managing the Global Epidemic. Report of a WHO Consultation, WHO Technical Report Series No. 894. Geneva: WHO, 2000.

18. Hills AP, King NA, Armstrong TP. The contribution of physical activity and sedentary behaviours to the growth and development of children and adolescents: implications for overweight and obesity. Sports Med 2007; 37 :533-45.

19. Brown T, Moore TH, Hooper L, et al. Interventions for preventing obesity in children. Cochrane Database Syst Rev. 2019;7:CD001871.

20. Hills AP, Okely AD, Baur LA. Addressing childhood obesity through increased physical activity. Nat Rev Endocrinol 2010;6:543-9.

21. Ludwig DS, Pollack HA. Obesity and the economy: from crisis to opportunity. JAMA 2009;301:533-5.

22. Janssen I, Katzmarzyk PT, Boyce WF, et al. Overweight and obesity in Canadian adolescents and their associations with dietary habits and physical activity patterns. $J$ Adolesc Health 2004;35:360-7.

23. Vandewater EA, Shim MS, Caplovitz AG. Linking obesity and activity level with children's television and video game use. $J$ Adolesc 2004;27:71-85.

24. Caroli M, Argentieri L, Cardone M, et al. Role of television in childhood obesity prevention. Int $\mathrm{J}$ Obes Relat Metab Disord 2004;28(Suppl 3):S1048.

25. Hesketh K, Wake M, Graham M, et al. Stability of television viewing and electronic game/computer use in a prospective cohort study of Australian children: relationship with body mass index. Int $J$ Behav Nutr Phys Act 2007; 4: 60.

26. Strong WB, Malina RM, Blimkie CJ, et al. Evidence based physical activity for school-age youth. J Pediatr 2005;146:732-7.

27. Barnett LM, Morgan PJ, van Beurden E, et al. Perceived sports competence mediates the relationship between childhood motor skill proficiency and adolescent physical activity and fitness: a longitudinal assessment. Int $J$ Behav Nutr Phys Act 2008; 5: 40.

28. Fogelholm M. Physical activity, fitness and fatness: relations to mortality, morbidity and disease risk factors. A systematic review. Obes Rev 2010;11:202-21. 
29. Dwyer T, Hosmer D, Hosmer T, et al. The inverse relationship between number of steps per day and obesity in a population-based sample: the AusDiab study. Int J Obes (Lond) 2007;31:797-804.

30. Thivel, D., Isacco, L., Rousset, S., Boirie, Y., Morio, B., \& Duché, P. Intensive exercise: a remedy for childhood obesity?. Physiology \& behavior, 2011;102, 132-136.

31. Hills AP, Andersen LB, Byrne NM. Physical activity and obesity in children. Br J Sports Med. 2011; 45: 866-70.

32. Koplan JP, Liverman CT, Kraak VI, Wisham SL. Progress in preventing childhood obesity: how do we measure up? Washington: National Academy Press, Institute of Medicine; 2007.

33. Barlow SE. Expert committee. Expert committee recommendations regarding the prevention, assessment, and treatment of child and adolescent overweight and obesity: summary report. Pediatrics. 2007; 120(Suppl 4):S164-92

34. Birch LL, Davison KK. Family environmental factors influencing the developing behavioral controls of food intake and childhood overweight. Pediatr Clin N Am. 2001;48(4):893-907

35. Sung-Chan P, Sung YW, Zhao X, Brownson RC. Family-based models for childhood-obesity intervention: a systematic review of randomized controlled trials. Obes Rev. 2013;14:265-78.

36. Manganello J, Blake N. A study of quantitative content analysis of health messages in U.S. Media from 1985 to 2005. Health Commun. 2010;25:387-96.

37. Danielsson P, Kowalski J, Ekblom Ö, Marcus C. Response of severely obese children and adolescents to behavioral treatment. Arch Pediatr Adolesc Med 2012; 166: 1103-8.

38. Chen AY, Escarce JJ. Family structure and childhood obesity, early childhood longitudinal study-kindergarten cohort. Prev Chronic Dis. 2010; 7:A50

39. Gibson LY, Byrne SM, Davis EA, Blair E, Jacoby P, Zubrick SR. The role of family and maternal factors in childhood obesity. Med J Aust. 2007;186: 591-5.

40. Robertson, W., Fleming, J., Kamal, A., Hamborg, T., Khan, K. A., Griffiths, F., ... \& Thorogood, M. (2017). Randomised controlled trial evaluating the effectiveness and cost-effectiveness of'Families for Health', a family-based childhood obesity treatment intervention delivered in a community setting for ages 6 to 11 years. Health Technology Assessment (Winchester, England), 21(1), 1.

41. Friedland O, Nemet D, Gorodnitsky N, Wolach B, Eliakim A. Obesity and lipid profiles in children and adolescents. J Pediatr Endocrinol Metab. 2002;15:1011-16

42. Belay B, Belamarich P, Racine AD. Pediatric precursors of adult atherosclerosis. Pediatr Rev. $2004 ; 25: 4-16$.

43. Velázquez-López, L., Santiago-Díaz, G., NavaHernández, J., Muñoz-Torres, A. V., MedinaBravo, P., \& Torres-Tamayo, M. . Mediterraneanstyle diet reduces metabolic syndrome components in obese children and adolescents with obesity. BMC pediatrics, 2014;14, 1-10.

44. Giannini, C., Diesse, L., D'adamo, E., Chiavaroli, V., De Giorgis, T., Di Iorio, C., ... \& Mohn, A.
(2014). Influence of the Mediterranean diet on carotid intima-media thickness in hypercholesterolaemic children: a 12-month intervention study. Nutrition, Metabolism and Cardiovascular Diseases,2014;24, 75-82. 